This is an electronic reprint of the original article. This reprint may differ from the original in pagination and typographic detail.

\author{
Author(s): Sikiö, Riitta; Siekkinen, Martti; Holopainen, Leena; Silinskas, Gintautas; Lerkkanen, \\ Marja-Kristiina; Nurmi, Jari-Erik
}

Title: $\quad$ Maternal parenting styles, homework help, and children's literacy development in language minority and Finnish-speaking families

Year: $\quad 2018$

Version:

Please cite the original version:

Sikiö, R., Siekkinen, M., Holopainen, L., Silinskas, G., Lerkkanen, M.-K., \& Nurmi, J.-E. (2018). Maternal parenting styles, homework help, and children's literacy development in language minority and Finnish-speaking families. European Journal of Psychology of Education, 33(2), 235-250. https://doi.org/10.1007/s10212-0170330-4

All material supplied via JYX is protected by copyright and other intellectual property rights, and duplication or sale of all or part of any of the repository collections is not permitted, except that material may be duplicated by you for your research use or educational purposes in electronic or print form. You must obtain permission for any other use. Electronic or print copies may not be offered, whether for sale or otherwise to anyone who is not an authorised user. 


\title{
STUDY 3. Maternal parenting styles, homework help, and children's literacy development in language minority and Finnish-speaking families
}

\begin{abstract}
The aim of this study was to examine the role of mothers' (language minority mothers, LM, $\mathrm{n}=49$, and Finnish-speaking mothers, MP, $n=368$ ) parenting styles and maternal help with their children's homework in the children's (mean age 11.43 years) literacy skills at fourth grade in Finland. In addition, the moderating effect of a child's gender on this relationship was investigated. The results showed that the LM mothers used psychological control more than MP mothers. Furthermore, the more LM mothers used warmth and psychological styles of parenting, the more they helped their daughters, not sons, with homework. The more LM mothers used behavioral control the less they helped the daughters. MP mothers' parenting styles did not relate to their children's reading and spelling skills. Maternal help negatively related to children's reading skills in both groups. This research provides new information to teachers and educators who work in multicultural teams. Because our findings could be applied in the educational settings of multilingual students, they are likely to be of great interest to the visionary scientists, researchers, teachers, and trainees.
\end{abstract}

\section{Keywords:}

Language minority children, Parenting styles, Reading, Spelling 


\section{Introduction}

Interaction between parents and children is an important interpersonal aspect of children's achievement and learning in school (Pianta, Nimez and Bennett 1997). Parental involvement at home affects children's school success (Castro, Expósito-Casas, López-Martin, Lizasoain, NavarroAsencio and Luis-Gaviria 2015). Talking with their child about school, supervision of homework, meeting with teachers, visiting their child's class, and collecting money for school trips are typical examples of involvement for both parents. These behaviors have been shown to predict positive outcomes for children, including academic skills (Hill and Taylor 2004; Pomerantz, Moorman and Litwack 2007). Different parenting styles also affect children's acculturation (Prady, Kierrnan, Fairlay and Wright 2013) and integration in the classroom (Nguen, Chang and Loh 2014), as well as in their new home country and its culture. In addition, mothers and fathers have different roles in parenting, and these roles vary in many countries (Newman, Gozu, Guan, Lee, Li, and Sasaki 2015). Home involvement does not always affect a child positively, and may matter more for some children than for others (Pomerantz et al. 2007; Silinskas, Niemi, Lerkkanen and Nurmi 2013).

Different parenting styles have been studied extensively and their effects demonstrated, but with mixed results. There has been less study on the parenting styles of parents in different language groups and their influence on children's academic skills. This study contributes to the existing literature by comparing the influences of two groups of mothers and children: Language Minority (LM) and Majority Population (MP). It examines the relations of parenting styles and maternal help with homework on the children's $4^{\text {th }}$ grade literacy skills: named decoding, reading comprehension and pseudoword spelling in Finnish.

\section{Parenting styles and children's academic skill development}

Differences in parenting styles are largely understood based on a theory developed by Baumrind (1966). Parenting styles can be categorized into three types: authoritative, authoritarian, and permissive. These three types of parenting differ in two basic dimensions: affection (warmth) and control. Authoritative parenting is characterized by parental affection and behavioral control, which have been shown to be positively correlated with outcomes of children of various ages (Baumrind 1989; Hart, Newell and Olsen 2003; Maccoby and Martin 1983). Authoritarian parenting is marked by high behavioral and punitive control (Hart et al. 2003) and low affection. Permissive parenting is defined by high affection and lower behavioral control (Baumrind 1989).

Studies have shown that authoritative parenting has positive effects on children's school performance (Steinberg, Elmen and Mounts 1989) and spelling skills in the first and second grades (Chao 2000; Karreman, van Tuijl, van Aken and Dekovic 2006; Kiuru et al. 2012; Wang, Chen, Chen, 
Cui and Li 2006). Warm relationships support and encourage children toward autonomy at a young age, and strengthen their social and academic functioning in early childhood (Landry, Smith and Swank 2006). Fletcher, Walls, Cook, Madison and Bridges (2008) reported that the highest levels of positive academic achievement are linked to authoritative parenting, while the highest levels of social problems in children are linked to authoritarian parenting. Along with permissive parenting, authoritarian parenting has negative effects on school success (Aunola and Nurmi 2005; Chen Main, Zhou, Bunge, Lau and Chu 2014; Coley, Lewin-Bizan and Carrano 2011).

In our view, the factors that affect behavior and, especially, academic skills in children from immigrant families are among the most interesting research targets (Hill 2001). Sparkman, Woodrow and Brown (2015) found significant differences in the parenting styles of Hispanic and AfricanAmerican parents in the United States: African-American parents were more likely to use warmth and support autonomy than Hispanic parents, while Hispanic parents were likely to use more coercion and rejection in their parenting. Chao (2000) investigated the parenting styles, home involvement and socialization goals of Chinese immigrant and European-American mothers in relation to their firstand third-grade children's school achievements. Chao found that Chinese mothers endorsed more authoritarian and permissive parenting styles than European-American mothers. However, few studies have reported on the effects of parenting styles and maternal help on children's achievement in the Language Minority (LM) context.

Common to the above studies is that Language Minority (LM) parents tend to be less educated than Majority Population (MP) parents, and this factor may affect parenting. Nam and Park (2015) studied the thoughts and practices of 106 immigrant parents and their children regarding their schools' efforts to strengthen three aspects of parental involvement: parenting, communication and learning at home. They found that mothers' educational levels correlated significantly to their children's English academic skills. The more the mothers were educated the more they communicate and teach their child at home. Additionally, parents with a higher socioeconomic background (SES) have been shown to demonstrate more warmth in their parenting practices and to engage in more developmental activities (Melhuish, Phan, Sylva, Sammons, Siraj-Blatchford and Taggart 2008).

In the current study, Finnish mothers (MP) and Language Minority (LM) mothers' education and home languages are controlled for, and the relations of parenting styles and help with homework on reading and spelling skills are used to control for academic skill development. Little has been studied about the relationship between parenting styles and children's gender. Mileva-Seitz et al. (2014) noted that boys were more vulnerable to effects of early parenting and boys were more sensitive to warm parenting than girls. Another research aim of the current study is to examine the different relations of mothers' parenting styles and influence of homework help on girls or boys. 
We appreciate that there is no one right way to parent or control a child. However, a parenting style with high warmth and caring control is generally associated with healthy and balanced child development (Darling and Steinberg 1993; Joussemet, Vitaro, Barker, Côté, Nagin, Zoccolillo and Tremblay 2008). On the contrary, children whose parents use a controlling parenting style were likely to require external control more than internal motivations (Lepper 1983). More information is needed about parenting styles and maternal help across equal socioeconomic language backgrounds and different cultural perspectives.

\section{Home involvement and children's literacy skills development}

In this study, children's literacy skills defined decoding, reading comprehension and pseudoword spelling. The process of reading primarily requires performance of the alphabetic principle formed by letter-sound knowledge and phonemic skills, followed by maintenance of the detected phoneme in short-term memory, synthesis of all the read phonemes and, finally, recognition of word meaning after generating the phoneme sequence (Goswami 2002). Literacy research has shown that spelling skills depend on linguistic factors such as word frequency (frequency effect) and lexical value (lexicality effect) (Defior, Martos and Cary 2002; Snowling 2000). In Finland, the phonemegrapheme correspondence method is commonly used in teaching reading and writing; Finnish language is orthographically very transparent, as a phoneme is almost always spelled or pronounced the same way. On average, most Finnish children read accurately before the end of the first grade (Holopainen, Ahonen and Lyytinen 2000).

Finnish education includes the preparatory Finnish language learning (Finnish 2) system. At least 900 hours/year are provided for immigrant/LM children aged 6 to 10, and 1000 hours/year for older children who come to Finland. After that, children begin basic Finnish education (Finnish Board of Education 2015). These Finnish 2 language lessons are for those whose mother language is not Finnish or Swedish and whose parents speak a language other than Finnish. In Finnish 2 lessons, children have the opportunity to learn everyday Finnish vocabulary, reading and writing skills, and to practice the Finnish language naturally in different situations.

In educational research, the term "home involvement" includes either both parents' involvement (parental involvement) or mothers' sole involvement (maternal home involvement). Different home involvement practices have been identified as critical to defining children's social development in diverse cultural and ethnic groups (Aunola and Nurmi 2005; Chao 2000; Lansford, Chang, Dodge, Malone, Oburu and Palmerus 2005; Steinberg, Dornbusch and Brown 1992). Tight, controlled parenting styles have been shown to negatively affect children, whereas effective socialization behaviors, such as the display of warmth and acceptance and suitable levels of control, 
have been shown to be associated with cognitive and behavioral competence in children (Baumrind 1966; Darling and Steinberg 1993; Hill 2001). Effective home involvement, such as help with reading, has proven to have a significant effect on children's academic skills (Sénéchal 2006) and motivation for learning (Blanch, Duran, Valdebenito and Flores 2013).

However, findings are contradictory. Some studies have shown a positive influence of home involvement on children's success in reading performance (Manolitsis, Georgiou and Parrila 2011; Pomerantz et al. 2007; Sénéchal and LeFevre 2002), rapid naming and vocabulary (Torppa, Poikkeus, Laakso, Eklund and Lyytinen 2006). However, other studies have shown that parental teaching has a negative effect on reading; that is, the more parents helped, the worse their children performed at school (Silinskas, Leppänen, Aunola, Parrila and Nurmi 2010). Parenting styles have also been associated with children's school performance. Behavioral control increased the occurrence of taskavoidant behavior, especially in boys, and a warm parenting style reduced anxiety in girls regarding school tasks during their first school year (Kervinen and Aunola 2013). Parents tend to react to their children's poor performance by increasing the frequency of help, and children who perform poorly are more likely to ask for help from their parents (Green, Walker, Hoover-Dempsey and Sandler 2007). Correspondingly, parents whose children perform well at school have been shown to help their children less than those whose children show poor reading skills (Ki and Soon 2012; Silinskas, Kiuru, Tolvanen, Niemi, Lerkkanen and Nurmi 2013). This study aims to determine the relation of different parenting styles and maternal help with homework on children's literacy skills, named decoding, reading comprehension and pseudoword spelling in Finnish.

\section{The present study}

In the present study, the relations of mothers' parenting styles and home involvement on their children's literacy skills were assessed in two different groups: the Language Minority (LM) group and the Majority Population (MP) group. The following research questions were formulated:

1. To what extent do Language Minority (LM) and Majority Population (MP) mothers differ in their parenting styles and homework help? To what extent do the relations of maternal parenting styles and help with homework on children's literacy skills (named decoding, reading comprehension and pseudoword spelling) differ between the Language Minority (LM) and Majority Population (MP) groups?

2. To what extent do the child's gender and mother's education influence the association between maternal parenting styles, maternal help with homework, and children's literacy skills (named decoding, reading comprehension and pseudoword spelling)?

\section{Method}




\section{Participants and procedure}

The current study is part of an extensive longitudinal study (Lerkkanen, Niemi, Poikkeus, Poskiparta, Siekkinen, \& Nurmi, 2006) in which an age cohort sample of Finnish children was followed from kindergarten (6 years of age, $\mathrm{N}=1,831)$ to grade four $(11$ years of age, $\mathrm{N}=1,887)$ to investigate the development of academic literacy skills (named decoding, reading comprehension and pseudoword spelling), home involvement and their associations with parent practices.

Participants were collected from three medium-sized towns and one municipality whose administration is based on residents' self-government: two in Central Finland, one in Eastern Finland, and one in Western Finland. At the outset of the study, children's parents and teachers were asked for their written consent at the beginning of kindergarten.

A subsample of the present study comprised 417 fourth-grade children and their mothers. This sample of Finnish children was reduced systematically so group sizes were comparable to improve the statistical reliability of the study. As not enough fathers responded, we used only the mothers' answers in this study.

Children's reading and spelling skills were measured in a group test in April 2011 at the end of fourth grade by trained testers studying teacher education or psychology. The children's mothers were asked to complete questionnaires during the spring term of fourth grade (April 2011).

Language minority group (LM). Children were classified as LM learners based on parental reports of a primary home language other than Finnish at school entry. The Language Minority (LM) group comprised $11.7 \%$ of the 417 children selected for the final sample, and consisted of 49 multilingual children ( 27 boys, 22 girls, mean age of 11.37 years) and 48 mothers. The Language Minority (LM) children participated in normal classes in primary school. They spoke a language other than Finnish at home and had lived in Finland at least since kindergarten (6 years old). The languages spoken at home were English (16 children), Russian (9), German (4), Swedish (3), Albanian (3), Italian (2), Arabic (1), Chinese (1), Estonian (1), Hungarian (1), Persian (1), Portuguese (1) Serbian (1), Somalian (1), Spanish (1), Thai (1), Turkish (1), and Vietnamese (1).

Majority population (MP). The comparison group consisted of 368 Finnish-speaking children (190 boys, 178 girls, mean age of 11.49 years in fourth grade).

\section{Measures}

Decoding. A group test was used to assess fourth-grade students' ability to decode a word-chain task (Nevala and Lyytinen 2000). The word-chain task was a time-limited test with 10 rows, involving 4 to 6 words written together without any spaces in between. The children silently read the words comprising the chains, then noted the word boundaries by drawing a division line between the words. 
The score comprised the number of correct responses (maximum of 40) within the time limit set (1 minute, 15 seconds). Cronbach's $\alpha$ for the tasks was .78.

Reading comprehension. Children's reading comprehension and reading fluency were evaluated using a TOSREC test (Test of Silent Reading Efficiency and Comprehension) (Wagner, Torgesen, Rashotte and Pearson 2009; Finnish version by Lerkkanen and Poikkeus 2009). The group test was administered in the spring of fourth grade. The test contained 60 statements or sentences. Each child had three minutes to choose from two alternatives (true or false) and circle the correct option. Children received one point for each correct answer. The maximum score was 60, and Cronbach's $\alpha$ was .85 . Pseudoword spelling. Spelling was assessed in grade four using a task with 8 items consisting of one-syllable pseudowords (2 items: kirk, vuil), three-syllable pseudowords (3 items: märstö, saihdin, and raalsku), and four-syllable pseudowords (3 items: voistoa, hiuruutti, and seivolssi) from the ARMI reading test battery (Lerkkanen, Poikkeus and Ketonen 2006). Each item was read orally twice. The score was the number of correct items (maximum value of 8). Cronbach's $\alpha$ for the tasks was .65 Parenting styles. Mothers' parenting styles were assessed using a Finnish version (Aunola and Nurmi 2005) of the Blocks' Child-Rearing Practices Report (CRPR; Roberts, Block and Block 1984), which consisted of 17 items on a 5-point scale $(1=$ does not fit me at all; $5=$ fits me very well $)$. The final summary variables are as follows. (1) Warmth included 10 items reflecting a positive relationship with the child ("I often tell my child that I appreciate what she/he tries or achieves"); Cronbach's $\alpha$ was .84. (2) Behavioral control included three items that reflected clear expectations of the child's behavior and the valuing of obedience in children ("My child should learn that we have rules in our family"); Cronbach's $\alpha$ was .69. (3) Psychological control included four items that reflected maternal attitudes toward guilt, pride and expressing disappointment ( "I believe the child should be aware of how much I have done for him/her"); Cronbach's $\alpha$ was .75.

Maternal help. Mothers' help with their children's homework was measured using three questions: (1) Do you teach your child with his/her homework? (2) Do you help or guide your child with his/her homework? (3) Do you help your child with his/her reading related homework? Answers were provided on a 5 -point scale (1=never, $5=$ =always). The 4 -item scale was originally published by Silinskas, Niemi, Lerkkanen and Nurmi (2013) and showed good internal consistency (.88-.91). In this study we used 3 items for reading and writing, omitting the math item (Cronbach's $\alpha .76$ ).

\section{Control variables}

Mothers' level of education. Mothers were asked to respond their level of education on a 3-point scale: (1) no vocation or vocational courses (MP group 4.4\%, LM group 4.1\%); (2) vocational school, 
vocational college, polytechnic or bachelor's degree (MP 46\%, LM 28.6\%); (3) master's degree, licentiate or doctoral degree (MP 41.4\%, LM 57.1\%).

\section{Results}

The means and standard deviations of all variables for the Language Minority (LM, N=49) and Majority Population (MP) groups $(\mathrm{N}=368)$ are shown in Table 1. An independent-sample t-test (SPSS, Version 21) was first used to determine the difference between LM and MP mothers' parenting styles and maternal help with homework. As can be seen in Table 1, while the LM mothers used more psychological control than did MP mothers, no significant differences were found between the groups in other measurements.

The correlations between all variables are shown separately for LM and MP in Table 2. In the LM group, the students' reading comprehension tests and mothers' help correlated negatively, and positively between the decoding test and the reading comprehension test. Psychological and behavioral control also correlated positively. In the MP group, inter-correlations were low, except for the positive correlations between the reading comprehension test and the decoding test, and between the uses of behavioral and psychological control. 
Table 1. Means, standard deviations, modes and t-tests of variables and mothers' answers in Language Minority (LM) and Majority Population (MP) groups.

\begin{tabular}{|c|c|c|c|c|c|c|c|c|c|c|}
\hline & $\underline{\mathbf{L M}}$ & & & $\underline{\text { MP }}$ & & & & & $\frac{95 \%}{\underline{\text { CI }}}$ & \\
\hline & M & SD & Mo & M & SD & Mo & $\mathrm{t}(\mathrm{df})$ & $\mathrm{p}$ & $\overline{\mathrm{LL}}$ & UL \\
\hline Reading comprehension & 46.77 & 9.48 & 60 & 48.05 & 8.83 & 60 & $.894(378)$ & ns & -1.53 & 4.08 \\
\hline Decoding & 17.38 & 7.59 & 10 & 17.61 & 7.26 & 16 & $416(415)$ & ns & -2.42 & 2.18 \\
\hline Pseudoword spelling & 6.76 & 1.20 & 7 & 6.73 & 1.32 & 8 & $413(415)$ & ns & -.42 & .40 \\
\hline Maternal help & 3.07 & 1.17 & 2 & 2.97 & .95 & 2 & $-54(56.81)$ & ns & -4.0 & .20 \\
\hline Warmth & 4.36 & .48 & 4.80 & 4.27 & .44 & 4.40 & $-1.25(317)$ & ns & -.23 & .05 \\
\hline Behavioral control & 3.77 & .52 & 3.75 & 3.74 & .51 & 3.75 & $-.34(62.29)$ & ns & -.18 & .13 \\
\hline Psychological control & 2.96 & .74 & 2.75 & 2.67 & .64 & 2.75 & $-.2 .80(317)$ & .05 & -.50 & -.08 \\
\hline Child's gender & 1.55 & .50 & 2 & 1.50 & .50 & 2 & $-.41(61.44)$ & ns & -.18 & .11 \\
\hline Mother's education & 2.59 & .58 & 3 & 2.40 & .58 & 2 & $-2.05(54.70)$ & ns & -.37 & -.00 \\
\hline
\end{tabular}




\section{Table 2}

Pearson's correlations of all measures among the fourth-grade majority population (MP) are shown in the upper section, and language minority (LM) correlations of all measures are shown in the lower section.

\begin{tabular}{|c|c|c|c|c|c|c|c|c|c|c|}
\hline & & 1 & 2 & 3 & 4 & 5 & 6 & 7 & 8 & 9 \\
\hline 1 & Reading comprehension & - & .53 & .24 & -.21 & .05 & .06 & .12 & -.12 & .10 \\
\hline 2 & Decoding & .60 & - & .27 & -.25 & .04 & .04 & -.00 & -.16 & .07 \\
\hline 3 & Pseudoword spelling & .19 & -.12 & - & -.30 & -.03 & .02 & .02 & -.16 & .06 \\
\hline 4 & Maternal help & -.41 & -.54 & .02 & - & .00 & .07 & .15 & .19 & -.13 \\
\hline 5 & Warmth & -.09 & -.03 & .03 & .01 & - & -.00 & -.00 & .00 & .14 \\
\hline 6 & Behavioral control & .15 & .24 & -.17 & .00 & .15 & - & .38 & .11 & -.01 \\
\hline 7 & Psychological control & .13 & .18 & -.12 & .21 & -.24 & .50 & - & .16 & -.10 \\
\hline 8 & Child's gender & .05 & -.09 & -.16 & -.05 & -.02 & .14 & .12 & - & .11 \\
\hline 9 & Mother's education & .05 & -.15 & -.32 & -.11 & .28 & .00 & -.25 & .11 & - \\
\hline
\end{tabular}

Note: $\mathrm{CI}=$ confidence interval; $\mathrm{LL}=$ lower limit; $\mathrm{UL}=$ upper limit, $\mathrm{ns}=$ non-significant.

Note:Significant $(p<.05)$ correlations are in boldface. 
A path model was constructed to answer the research questions on the relationship between maternal parenting styles, maternal homework help and children's literacy skills. In the path model, all three literacy outcomes were regressed regarding maternal help with homework. Maternal help with homework was regressed on all three variables for parenting style. Correlations among literacy skills (reading comprehension, pseudoword spelling and decoding) were determined. Maternal education was the control variable in all analyses.

Concurrent associations were allowed between all independent variables. These relations were analyzed separately for two groups in two distinct models, Language Minority (LM) and Majority Population (MP), after a multi-group differentiate test $(\mathrm{p}<.005)$ showed it to be necessary. The indirect paths were estimated from each of three parenting styles to each of the literacy skills via maternal help. Finally, we applied a multigroup- method in both models (LM and MP) to investigate the effect of children's gender and after that the effect of mother's education. Additional information was thus obtained on the relationship between maternal parenting styles, maternal help and children's literacy skills. For the final models, non-significant paths were fixed to zero.

The Mplus statistical package (Version 7.11; Muthén and Muthén 2012) was used in the path model. The proportions of missing data for the main study variables ranged from $4.1 \%$ to $25.9 \%$ (LM: $M=4.7 \%$, RANGE $0 \%-10.2 \%$; MP: $M=12.8 \%$, RANGE $0 \%-25.9 \%$ ). The missing data were adjusted by using the random test (Little's MCAR test in LM: $\chi^{2}=42.56$, df $=48, p=.695$; Little's MCAR test in MP: $\chi^{2}=92.62, \mathrm{df}=86, \mathrm{p}=.293$ ).

The parameters of the models were estimated using a full-information maximum likelihood estimation with standard errors that were robust against non-normal distributions (Muthén and Muthén 1998-2012). As distributions of the variables were skewed, the model parameters were estimated using the MLR estimator, which produces standard errors and chi-square test statistics for missing data with non-normal outcomes by means of a sandwich estimator.

For all models, goodness-of-fit was evaluated using five indicators: the $\chi^{2}$ test; the comparative fit index (CFI); the Tucker-Lewis Index (TLI); the Root Mean Square Error of Approximation (RMSEA); and the Standardized Root Mean Square Residual (SRMR). According to Hu and Bentler (1999), a non-significant $\chi^{2}$ test, TLI and CFI values above .95, RMSEA values below .06 and SRMR values close to .08 can be considered indicators of good model fit to the data. CFI and TLI values below .90 and RMSEA and SRMR values above .10 are indications of a poor model fit (Kline 2005).

\section{Mothers' parenting styles and maternal help in the language minority (LM) group}


For the LM group with gender as a moderator, after fixing non-significant paths to zero, the model fit the data well: $\chi^{2}(26 \mathrm{~N}=47)=38.74, \mathrm{p}=.26, \mathrm{CFI}=0.92, \mathrm{TLI}=0.90, \mathrm{RMSEA}=.08, \mathrm{SRMR}=$ .10. Results (Figure 1) showed that mothers' warmth and psychological parenting styles correlated positively and behavioral control negatively to helping girls. In addition, the less LM mothers helped their children, whether girls or boys, the better their children succeeded on both the decoding and reading comprehension tests. Mothers' help and parenting styles did not influence success on the pseudo word spelling test.

Figure 1. The standardized estimates for the Language Minority (LM) group girls (black) and boys (grey): model of mothers' parenting styles, maternal help and children's reading and spelling skills.

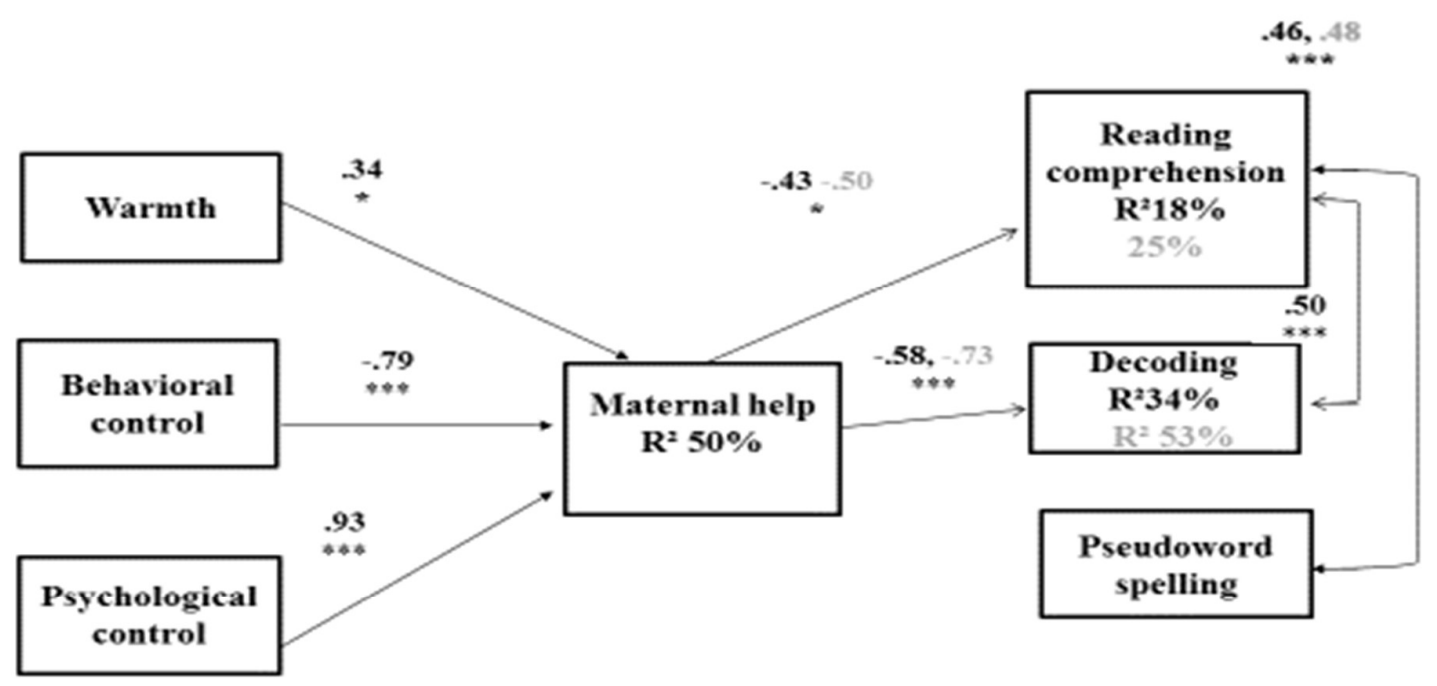

Note $* p<.05, * * p<.01,{ }^{* * *} p<.001$. 
The results also showed a significant positive indirect relation of LM mothers' behavioral control on reading comprehension skills $(.35, \mathrm{p}<.01)$ and decoding skills $(.46, \mathrm{p}<.01)$ with maternal help. There was also a significant negative indirect relation of mothers' psychological control on reading comprehension skills $(-.41, \mathrm{p}<.01)$ and decoding skills with maternal help $(-.56, \mathrm{p}<.001)$.

\section{Mothers' parenting styles and maternal help in the majority population (MP) group}

For the MP group, after fixing non-significant paths to zero, the model fit the data well: $\chi^{2}(29 \mathrm{~N}=$ $269)=25.75, \mathrm{p}=.84, \mathrm{CFI}=1.00, \mathrm{TLI}=1.10, \mathrm{RMSEA}=.00, \mathrm{SRMR}=.05$. The results showed that the less MP mothers helped their children with homework, the better scores they had in reading comprehension, decoding and pseudo word spelling. As for the research question "to what extent do children's gender and mothers' education influence the association between maternal parenting styles, maternal help with homework, and children's literacy skills (named decoding, reading comprehension and pseudo word spelling)", the results showed that the higher the mothers' education level, the less they helped their daughters (Figure 2). 
Figure 2. The standardized estimates for the Majority Population (MP) group girls (black) and boys (grey): model of mothers' parenting styles, maternal help and reading and spelling skills.

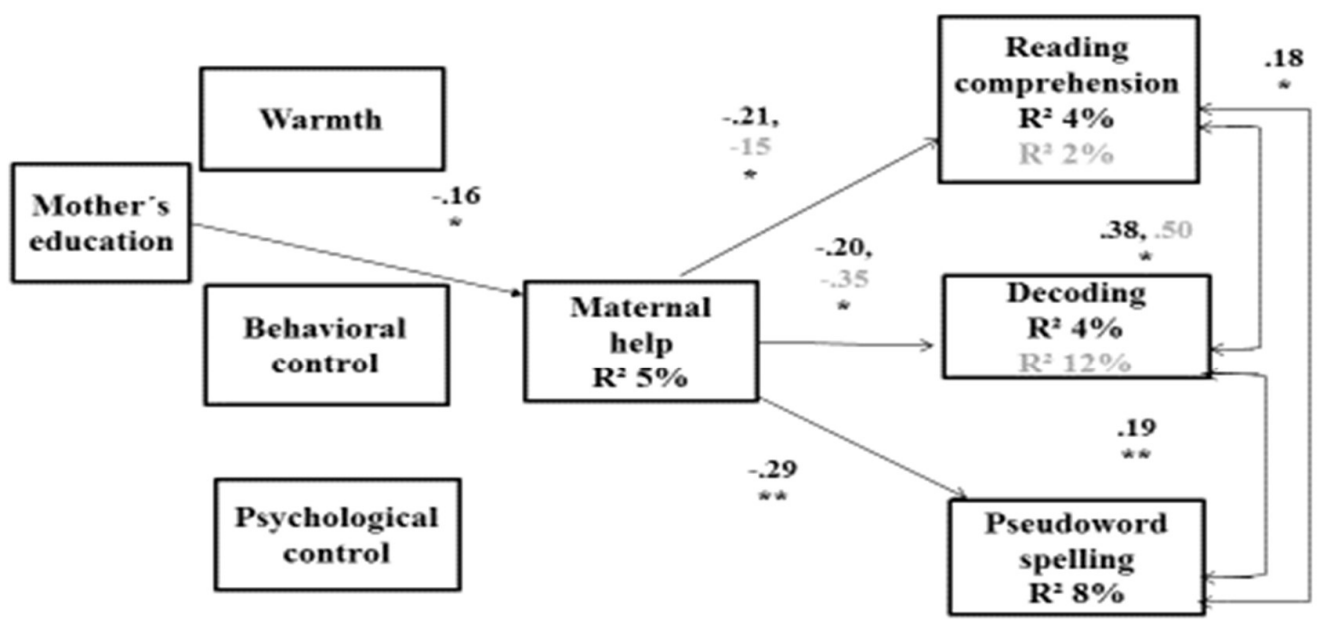

Note: $* p<.05, * * p<.01, * * * p<.001$.

\section{Discussion}

In the present study, we examined the relations of mothers' parenting styles and maternal help on their children's reading comprehension, decoding and pseudo word spelling skills in LM and MP children. The primary result was that mothers' parenting styles and maternal help in these two groups turned out very differently, and partly depended on the gender of the child. First, LM mothers used significantly more psychological control in their parenting than did MP mothers. Second, the more LM mothers used warmth and psychological styles of parenting, the more they helped their daughters, not sons, with homework. Third, the higher the mothers' education, the less they helped their daughters.

Overall, the average level of literacy skills for both groups at the end of fourth grade was high. This is partly due to the high quality of the Finnish 2 language system and Finnish education in general. Parenting styles and maternal homework help influenced children's reading comprehension and decoding skills and mothers' psychological control highly influenced both maternal help and 
children's reading comprehension and decoding skills. Previous studies showed that psychological control appears to negatively influence children's school performance (Aunola and Nurmi 2005; Chen, Liu and Li 2000; Chen et al. 2014; Coley et al. 2011; Ginsburg and Bronstein 1993). Moreover, a warm mother-child relationship encourages and supports children and has a positive relation on children's academic skills (Landry et al. 2006).

Interestingly, the behavioral control style of parenting influenced positively indirectly through the maternal help decoding and reading comprehension skills in the LM group. The result confirms earlier research that demonstrated the positive relations of relative warm and authoritative parenting with moderate control, which also offers a positive outcome in school achievement (Steinberg et al. 1989; Cox and Paley 2003; Landry et al. 2006; Fletcher et al. 2008; Newman et al. 2015). The parenting style of LM mothers can be explained in terms of warm mother-daughter relationships and mothers' trust in their children's abilities (see Sikiö, Holopainen, Siekkinen, Silinskas, Lerkkanen and Nurmi 2016), which strengthen intrinsic motivation. This positive cycle enables a child's success with literacy.

What explanations can be found for the differences in the LM group? Previous findings suggest that the effects of psychological control can vary between different cultures, as mothers engage in dissimilar levels of parenting. LM parents (see Renzaho, Green, Mellor and Swinburn 2011) may demand obedience, hold high expectations, scrutinize their children's behavior and use discipline. The native Finnish population, on the other hand, seems to prefer a positive and warm parenting style. This cultural difference may manifest itself in questionnaire answers regarding psychological control; in this way, it could appear to negatively influence educational thinking.

In this study, LM group children comprised eighteen different countries, and their parenting styles differed from Finnish parenting styles, indicating the relations of different cultures on parenting styles. The explanation for different parenting styles could also be found in cultural differences surrounding raising children. Mothers' sensitivity to their children's learning Finnish and its difficulties could cause them to exercise more psychological control. Like the Language Minority (LM) mothers in this study, mothers who cannot speak native Finnish properly have more difficulty helping their children with Finnish literacy tasks (Aram 2007). Different parenting styles may also be related to acculturation (Prady et al. 2013). The new home country, in this case Finland, could offer a limited or even poor culture that families do not want to identify with. This could influence both LM parents' knowledge of the MP school system and their ability to help with homework. For example, teachers give daily homework assignments to their pupils according to grade level. Homework is not required for preschool, but first and second grade usually requires thirty minutes to one hour of homework each day, and one to two hours for a child in third or fourth grade. Most 
homework tasks are designed to reinforce what has been taught in class, but in the upper grades children are increasingly expected to acquire additional information at home by means such as the internet. Parents with insufficient knowledge of the Finnish language or educational system may experience difficulties in helping their children.

Integration may facilitate the adaptation of LM groups to the MP (Nguen et al. 2014). The results of this study indicate that LM children were integrated to the Finnish school system from the beginning of their schooling, which likely explains their success on reading comprehension, decoding and pseudoword spelling tests. A multicultural environment could also benefit different families and parenting styles by integrating new families into the Finnish school culture and homework traditions. For example, it is notable that psychological control is a norm in Asian culture (Pomerantz and Wang 2009). LM children from Asia are accustomed to hard discipline because it is a part of their culture. Mothers having psychological control is a well-respected and accepted parenting style in a large part of the world. (Chao and Kanatsu 2008; Kim and Hong 2007). In this day and age, when children from different cultures increasingly move around the world, it is important to understand their background and how it influences parenting.

The results of maternal help regarding children's academic skills showed a negative impact on reading comprehension and decoding skills for both groups, and on the pseudoword spelling test for the MP group. This means that the less mothers helped their children, the better their children's success in reading tests. This result is consistent with previous studies (Sikiö et al. 2016; Silinskas, Niemi, et al. 2013), indicating that if the children are competent, there is no need to help them at home.

It is important to discuss the role of children's gender, mothers' education and parenting styles and mothers' help with homework on children's reading and spelling skills. Different parenting styles influenced mothers' home involvement with girls in the LM group; the less LM mothers helped, the better the girls succeeded in both reading comprehension and decoding tests. In addition, the MP mothers' home involvement negatively influenced girls' performance on the pseudoword test.

Regarding the results of mothers' education, the higher the education of MP mothers, the less they helped their children (see also Ki and Soon 2012). In our study, an explanation for this could be that Finnish mothers tend to place high trust in the school system (Lerkkanen, Kikas, Pakarinen, Poikonen and Nurmi 2013) and/or the level of mothers' education. The higher they were educated the more they trusted their children's skills (Sikiö et al. 2016).

\section{Limitations}


There are some limitations in the current study that must be taken into consideration. The LM sample size was small, which could have affected the analysis and generalizability of the results. However, the total number of immigrant children is limited in Finland overall; 5.5\% of all school children are immigrants, and 3.7\% of immigrant children are immigrants who do not speak Finnish, which means that the proportion of LM children in this study is statistically representative of the Finnish context (Statistic Finland 2015).

In addition, the LM group was heterogeneous; the families represented 18 different languages, and therefore no generalizations can be made for any one language. It is notable that in this study LM mothers used languages other than Finnish at home, but we did not record their Finnish language proficiency. We should have asked whether they used other languages (including Finnish) as well. Moreover, only mothers reported their parenting styles and levels of help with homework. Research demonstrates that mothers and fathers have different roles in parenting and that these roles vary by country (Newman et al. 2015). This aspect would have been interesting to study alongside the impact of fathers' parental involvement, but their response rate was too low. Finally, the mothers' support may have been biased either for or against the development of children's academic skills.

\section{Practical Implications}

The number of immigrants and LM children in Finland has historically been quite low, but has recently increased; this makes it even more important to examine the questions raised in this study in order to compare Finland's situation with that of other countries. We hope that the results will be taken into account when guiding and supporting relationships between parents, students and teachers. Although parenting issues are complex and difficult, thanks to meeting with parents and teachers the results of our study could raise discussions about parenting styles and their impact on academic achievement. The knowledge of orthographical differences is important for teachers when teaching children to read and spell. The change from deep orthographic system to transparent letter sound mapping system may cause difficulties for some LM children.

\section{Conclusion}

Mothers in the LM group used significantly more psychological control in their parenting than did MP mothers. Behavioral control influenced positively, and psychological control negatively indirectly through the maternal help to reading skills in the LM group. The higher the mother's education, the less they helped their daughters. This study opens up a new way of thinking about parenting styles and their different influences on school success. 


\section{References}

Aram, D. (2007). Sensitivity and consistency of maternal writing mediation to twin kindergartners. Early Education and Development, 18, 71-92.

Aunola, K., \& Nurmi, J.-E. (2005). The role of parenting styles in children's problem behaviour. Child Development, 76, 1144-1159.

Baumrind, D. (1966). Effects of authoritative parental control on child behaviour. Child Development, 37(4), 887-907.

Baumrind, D. (1989). Rearing competent children. In W. Damon (Ed.), Child development today and tomorrow (pp. 349-378). San Francisco, CA: Jossey-Bass.

Blanch, S., Duran, D., Valdebenito, V., \& Flores, M. (2013). The effects and characteristics of family involvement on a peer tutoring programme to improve reading comprehension competence. European Journal of Psychology of Education, 28, 101-119.

Castro, M., Expósito-Casas, E., López-Martín, E., Lizasoain, L., Navarro-Asencio, E., \& Luis Gaviria, J. (2015). Parental involvement on student academic achievement: A meta-analysis. Educational Research Review, 14, 33-46.

Chao, R. K. (2000). The parenting of immigrant Chinese and European American mothers: Relations between parenting styles, socialization goals, and parental practices. Journal of Applied Development Psychology, 21(2), 233-248.

Chao, R., \& Kanatsu, A. (2008). Beyond socioeconomics: Explaining ethnic group differences in parenting through cultural and immigration processes. Applied Developmental Science, 12, 181 187.

Chen, S. H., Main, A., Zhou, Q., Bunge, S. A., Lau, N., \& Chu, K. (2014). Effective control and early academic achievement of Chinese American children in immigrant families. Early Childhood Research Quarterly, 30, 45-56.

Chen, X., Liu, M., \& Li, D. (2000). Parental warmth, control, and indulgence and their relations to adjustment in Chinese children: A longitudinal study. Journal of Family Psychology, 14, $401-419$.

Coley, R. L., Lewin-Bizan, S., \& Carrano, J. M. (2011). Does early paternal parenting promote lowincome children's long-term cognitive skills? Journal of Family Issues, 32(11), 1522-1542.

Cox, M. J., \& Paley, B. (2003). Understanding families as systems. Current Directions in Psychological Science, 12, 193-196.

Darling, N., \& Steinberg, L. (1993). Parenting style as context: An integrative model. Psychological Bulletin, 113, 487-496. 
Defior, S., Martos, F. \& Cary, L. (2002). Differences in reading acquisition development in two shallow orthographies: Portuguese and Spanish. Applied Psycholinguistics, 23, 135-148.

Finnish National Board of Education. (2015). National core curriculum for instruction preparing immigrants for basic education.

Fletcher, A. C., Walls, J. K., Cook, E. C., Madison, K. J., \& Bridges, T. H. (2008). Parenting styles as a moderator of associations between maternal disciplinary strategies and child well-being. Journal of Family Issues, 29(12), 1724-1744.

Ginsburg, G. S., \& Bronstein, P. (1993). Family factors related to children's intrinsic/extrinsic motivational orientation and academic performance. Child Development, 64, 1461-1474.

Goswami, U. (2002). Phonology, reading development and dyslexia: A cross-linguistic perspective. Annals of Dyslexia, 52, 141-163.

Green, C. I., Walker, J. M. T., Hoover-Dempsey, K. V., \& Sandler, H. M. (2007). Parents' motivations for involvement in children's education: An empirical test of a theoretical model of parental involvement. Journal of Educational Psychology, 99, 535-544.

Hart, C. H., Newell, L. D., \& Olsen, S. F. (2003). Parenting skills and social/communicative competence in childhood. In J. O. Greene \& B. R. Burleson (Eds.), Handbook of communication and social interaction skills (pp.753-797). Mahwah, NJ: Lawrence Erlbaum.

Hill, N. E. (2001). Parenting and academic socialization as they relate to school readiness: The roles of ethnicity and family income. Journal of Educational Psychology, 93, 686-697.

Hill, N. E., \& Taylor, L. C. P. (2004). Parental school involvement and children's academic achievement: Pragmatics and issues. Current Directions in Psychological Science, 13, 161-164.

Holopainen, L., Ahonen, T., Tolvanen, A., \& Lyytinen, H. (2000). Two alternative ways to model the relation between reading accuracy and phonological awareness at preschool age. Scientific Studies of Reading, 4(2), 77-100.

Joussemet, M., Vitaro, F., Barker, E. D., Côté, S., Nagin, D. S., Zoccolillo, M., \& Tremblay, R. E. (2008). Controlling parenting and physical aggression during elementary school. Child Development, 79, 411-425.

Karreman, A., van Tuijl, C., van Aken, M. A. G., \& Dekovic, M. (2006). Parenting and self-regulation in preschoolers: A meta-analysis. Infant and Child Development, 15, 561-579.

Kervinen, S., Aunola, K. (2013). Vanhempien kasvatustyylien yhteys lasten koulussa käyttämiin työskentelytapoihin [Correlations of parenting styles and children's working methods in school]. Psykologia, 48, 4-16. 
Ki, S. L., \& Soon, H. K. (2012). Socioeconomic background, maternal parenting style and the language ability of five- and six-year-old children. Social Behavior \& Personality: An International Journal, 40(5), 767-781.

Kim, E., \& Hong, S. (2007). First generation Korean American parents' perceptions of discipline. Journal of Professional Nursing, 23, 60-68.

Kiuru, N., Aunola, K., Torppa, M., Lerkkanen, M.-K., Poikkeus, A.-M., Niemi, P., Viljaranta, J., Lyyra, A.-L., Leskinen, E., Tolvanen, A., \& Nurmi, J.-E. (2012). The role of parenting styles and teacher interactional styles in reading and spelling development. Journal of School Development, 50, 799-823.

Kline, R. B. (2005). Principles and practices of structural equation modelling. Methodology in the social sciences. New York, NY: Guildford Press.

Landry, S. H., Smith, K. E., \& Swank, P. R. (2006). Responsive parenting: Establishing early foundations for social, communication and independent problem-solving skills. Development Psychology, 42, 627-642.

Lansford, J. E., Chang, L., Dodge, K. A., Malone, P. S., Oburu, P., Palmerus, K., et al. (2005). Physical discipline and children's adjustment: Cultural normativeness as a moderator. Child Development, 76(6), 1234-1246.

Lepper, M. R. (1983). Social control processes and the internalization of social values: An attributional perspective. In E. T. Higgins, D. N. Ruble, \& W. W. Hartup (Eds.), Social cognition and social development (pp. 294-330). New York: Cambridge University Press.

Lerkkanen, M.-L., Niemi, P., Poikkeus, A.-M., Poskiparta, M., Siekkinen, M., \& Nurmi, J.-E.(2006). The ongoing first step study. Joensuu and Turku, Finland: Universites of Jyväskylä.

Lerkkanen, M.-K., Poikkeus, A.-M., \& Ketonen, R. (2006). ARMI - Luku - ja kirjoitustaidon arviointimateeriaali 1. luokalle [ARMI - The test material of reading and writing skills for the first grade]. Helsinki, Finland: WSOY.

Lerkkanen, M.-K., Kikas, E., Pakarinen, E., Poikonen, P.-L., \& Nurmi, J.-E. (2013). Mothers' trust toward teachers in relation to teaching practices. Early Childhood Research Quarterly, 28, $153-165$.

Maccoby, E., \& Martin, J. (1983). Socialization in the contexts of the family: Parent-child interactions. In E. M. Hetherington \& P. H. Mussen (Eds.), Handbook of child psychology (Series Ed). Socialization, personality, and social development, 4. (pp. 1-102) New York, NY: Wiley.

Manolitsis, G., Georgiou, G., \& Parrila, R. (2011). Revisiting the home literacy model of reading development in an orthographically consistent language. Learning and Instruction, 21, 496-505. 
Melhuish, E. C., Phan, M. B., Sylva, K., Sammons, P., Siraj-Blatchford, I., \& Taggart, B. (2008). Effects of the home learning environment and preschool center experience upon literacy and numeracy development in early primary school. Journal of Social Issues, 64(1), 95-114.

Mileva-Seitz, V. R., Ghassabian, A., Bakermans-Kranenburg, M. J., van den Brink, J. D., Linting, M., Jaddoe, V. W. V., Hofman, A., Verhulst, F. C., Tiemeier, H., \& van Ijzendoorn, M. H. (2014). Are boys more sensitive to sensitivity? Parenting and executive function in preschoolers. Journal of Experimental Child Psychology, 130, 193-208.

Muthén, L., \& Muthén, B. O. (1998-2012). Mplus version 7.11 \& Mplus user's guide. Retrieved from http//www.statmodel.com.

Nam, B.-H., \& Park, D.-B. (2015). Parent involvement: Perceptions of recent immigrant parents in a suburban school district, Minnesota. Educational Studies, 40(3), 310-329.

Nevala, J., \& Lyytinen, H. (2000). Sanaketjutesti [Differentiate word test]. Niilo Mäki Instituutti \& Jyväskylän yliopiston lapsitutkimuskeskus.

Newman, J., Gozu, H., Guan, S., Lee, J. E., Li, X., \& Sasaki, Y. (2015). Relationship between maternal parenting style and high school achievement and self-esteem in China, Turkey, and U.S.A. Journal of Comparative Family Studies, 46(2), 265-288.

Nguen, T., Chang, P. P. W., \& Loh, J. I. (2014). The psychology of Vietnamese tiger mothers: Qualitative insights into the parenting beliefs and practices of Vietnamese-Australian mothers. Journal of Family Studies, 20, 48-65.

Pianta, R. C., Nimez, S. L., \& Bennett, E. (1997). Mother-child relationships, teacher-child relationships, and school outcomes in preschool and kindergarten. Early Childhood Research Quarterly, 12, 263-280.

Pomerantz, E. M., Moorman, E. A., \& Litwack, S. D. (2007). The how, who, and why of parents' involvement in children's academic lives: More is not always better. Review of Educational Research, 77, 373-410.

Pomerantz, E. M., \& Wang, Q. (2009). The role of parental control in children's development in western and East Asian Countries. Current Direction in Psychological Science, 18(5), 285-289.

Prady, S. L., Kiernan, K., Fairlay, L., \& Wright, J. (2013). Parenting and infant temperament amongst Pakistani woman living in the UK according to country of birth: Results from the born in Bradford cohort study. Child Care in Practice, 19(4), 375-396.

Renzaho, A. M. N., Green, J., Mellor, D., \& Swinburn, B. (2011). Parenting, family functioning and lifestyle in a new culture: The case of African migrants in Melbourne, Victoria, Australia. Child \& Family Social Work, 16(2), 228-240. 
Roberts, G. C., Block, H., \& Block, J. (1984). Continuity and change in parents' child-rearing practices. Child Development, 55, 586-597.

Sénéchal, M., \& LeFevre, J.-A. (2002). Parental involvement in the developing of children's reading skills: A five-year longitudinal study. Child Development, 73, 445-460.

Sénéchal, M. (2006). Testing the home literacy model: Parent involvement in kindergarten is differentially related to grade 4 reading comprehension, fluency, spelling, and reading for pleasure. Scientific Studies of Reading, 10, 59-87.

Sikiö, R., Holopainen, L., Siekkinen, M., Silinskas, G., Lerkkanen, M.-K., \& Nurmi, J.-E. (2016). Maternal literacy teaching, causal attributions and children's literacy skills in Finnish-speaking and language minority families. International Journal of Educational Research, 77, 99-108.

Silinskas, G., Kiuru, N., Tolvanen, A., Niemi, P., Lerkkanen, M.-K., \& Nurmi, J.-E. (2013). Maternal teaching of reading and children's reading skills in grade 1: Patterns and predictors of positive and negative associations. Learning and Individual Differences, 27, 54-66.

Silinskas, G., Leppänen, U., Aunola, K., Parrila, R., \& Nurmi, J.-E. (2010). Predictors of mothers' and fathers' teaching of reading and mathematics in kindergarten and grade 1. Learning and Instruction, 20, 61-71.

Silinskas, G., Niemi, P., Lerkkanen, M.-K., \& Nurmi, J.-E. (2013). Children's poor academic performance evokes parental homework assistance — but does it help? International Journal of Behavioral Development, 37, 44-56.

Snowling, M. J. (2000). Dyslexia. Oxford: Blackwell Publishers.

Sparkman, N., Woodrow, K., \& Brown, K. (2015). Parenting differences in minority families: Implications for practice in Hispanic and African American families. The International Journal of Interdisciplinary Cultural Studies, 9(2), 1-12.

Statistics Finland. (2015). Retrieved from http://www.stat.fi/til/muutl/index_en.html

Steinberg, L., Dornbusch, S. M., \& Brown, B. B. (1992). Ethnic differences in adolescent achievement: An ecological perspective. American Psychologist, 47, 723-729.

Steinberg, L., Elmen, J. D., \& Mounts, N. S. (1989). Authoritative parenting, psychological maturity, and academic success among adolescents. Child Development, 60, 1424-1436.

Torppa, M., Poikkeus, A.-M., Laakso, M.-L., Eklund, K., \& Lyytinen, H. (2006). Predicting delayed letter knowledge development among children with and without familial risk for dyslexia. Development Psychology, 42, 1138-1142.

Wagner, R. K., Torgesen, J. K., Rashotte, C. A., \& Pearson N. A. (2009). TOSREC: Test of Sentence Reading Efficiency and Comprehension. Pro-Ed, Austin, TX. 
Wang, L., Chen, X., Chen, H., Cui, L., \& Li, M. (2006). Affect and maternal parenting as predictors of adaptive and maladaptive behaviors in Chinese children. International Journal of Behavioral Development, 30(2), 158-166. 
